Chi, Tailan. (1996) Collaborative Ventures and Value of Learning: Integrating the Transaction Cost and Strategic Option Perspectives on the Choice of Market Entry Modes. Journal of International Business Studies, 27 (2), 285-307. Publisher's Official Version:

http://www.jstor.org/stable/155286 Open Access Version: http://kuscholarworks.ku.edu/

[This document contains the author's accepted manuscript. For the publisher's version, see the link in the header of this document.]

\title{
Collaborative Ventures and Value of Learning: Integrating the Transaction Cost and Strategic Option Perspectives on the Choice of Market Entry Modes
}

\author{
By Tailan Chi and Donald J. McGuire \\ The University of Kansas and The University of Wisconsin-Milwaukee
}

Paper citation:

Chi, Tailan. (1996) Collaborative Ventures and Value of Learning: Integrating the Transaction Cost and Strategic Option Perspectives on the Choice of Market Entry Modes. Journal of International Business Studies, 27 (2), 285-307.

\begin{abstract}
:
This paper employs a simple stochastic model to investigate how transaction cost and strategic option considerations interact to influence a firm's evaluation of collaborative venturing as a market entry mode. After demonstrating how uncertainty about the market and about the potential partner can add to the value of a collaborative venture, the paper explicates a condition under which the option to acquire or sell out generates a positive economic value for both of the partners. The interaction of transaction cost and strategic option considerations is then examined, and a number of testable hypotheses are proposed based on the theoretical analyses of the paper.
\end{abstract}


COLLABORATIVE VENTURES AND VALUE OF LEARNING: INTEGRATING THE

TRANSACTION COST AND STRATEGIC OPTION PERSPECTIVES ON THE

CHOICE OF MARKET ENTRY MODES

\author{
Tailan Chi* and Donald J. McGuire** \\ University of Wisconsin-Milwaukee
}

*Tailan Chi (Ph.D., University of Washington) is Assistant Professor of International Business in the School of Business Administration, University of Wisconsin-Milwaukee. His research interests include interfirm exchange in knowledge-based assets, investment decision making under uncertainty, and organization structure of multinational enterprises.

**Donald J. McGuire is a Doctoral Candidate in the School of Business Administration, University of Wisconsin-Milwaukee. His research interests include real options, fixed income securities, and foreign exchange markets.

We are grateful to Paul Beamish, Editor of JIBS, and to three anonymous reviewers for their constructive comments and valuable suggestions. All remaining errors, however, are solely our own responsibility.

Published in the Journal of International Business Studies, 27(2): 285-307, 1996. 


\title{
Collaborative Ventures and Value of Learning: Integrating the Transaction Cost and Strategic Option Perspectives on the Choice of Market Entry Modes
}

\begin{abstract}
This paper employs a simple stochastic model to investigate how transaction cost and strategic option considerations interact to influence a firm's evaluation of collaborative venturing as a market entry mode. After demonstrating how uncertainty about the market and about the potential partner can add to the value of a collaborative venture, the paper explicates a condition under which the option to acquire or sell out generates a positive economic value for both of the partners. The interaction of transaction cost and strategic option considerations is then examined, and a number of testable hypotheses are proposed based on the theoretical analyses of the paper.
\end{abstract}


Chi, Tailan. (1996) Collaborative Ventures and Value of Learning: Integrating the Transaction Cost and Strategic Option Perspectives on the Choice of Market Entry Modes. Journal of International Business Studies, 27 (2), 285-307. Publisher's Official Version:

http://www.jstor.org/stable/155286 Open Access Version: http://kuscholarworks.ku.edu/

\section{INTRODUCTION}

The managers of a multinational enterprise (MNE) who are considering entry into a new market often must make decisions under highly uncertain and changeable circumstances. The variables that have a potentially significant impact on the prospect for its success in the market typically are large in number and keep evolving over time due to continual arrival of new information. A key decision the firm's management faces is whether to go it alone or collaborate with a local partner in entering the new market. It is well accepted among scholars of international business that a collaborative venture $(\mathrm{CV})$ is not economically justified unless there exists some complementarity between the resources of the participants [Contractor and Lorange 1987; Root 1987]. However, as suggested by the transaction cost perspective [Beamish and Banks 1987; Gomes-Casseres 1990; Hennart 1988], the existence of synergy between the two firms is not sufficient to justify collaborative venturing because they could also exploit the synergy by acquiring the other's complementary assets. In order for a CV to be the optimal arrangement, the two firms must also face some transaction cost problems that make the acquisition of the other firm or part thereof economically inefficient.

Although uncertainty lies in the root of any transaction cost problems [Williamson 1975], extant theoretical analyses under the transaction cost perspective have rarely examined how the potential changes in the uncertain variables might alter the assessment of alternative market entry modes. Consider the uncertainty facing two firms involved in a CV, for instance. Although both of them may foresee opportunities to acquire some valuable know-how from the other, it is often highly uncertain how much knowledge will be actually transferred between them due to potential transaction cost problems. But after the venture is started, it will eventually become clear how much knowledge they each can gain from the other. A question that naturally arises is: How will the expected revelation of this information affect each party's ex ante assessment of the CV when they are negotiating such an arrangement? In the ensuing sections of this paper, we will try to answer a number of questions like this using analytical tools of the strategic option perspective. 
Chi, Tailan. (1996) Collaborative Ventures and Value of Learning: Integrating the Transaction Cost and Strategic Option Perspectives on the Choice of Market Entry Modes. Journal of International Business Studies, 27 (2), 285-307. Publisher's Official Version: http://www.jstor.org/stable/155286 Open Access Version: http://kuscholarworks.ku.edu/

The distinguishing presumption of the strategic option perspective is that managers will alter their decisions when such changes are justified by new conditions that may emerge in an uncertain and dynamically evolving environment. Based on this presumption, if a decision to be made now has a chance of being altered later due to the arrival of new information, then the economic consequences of such changes should be properly accounted for when evaluating the current decision. For example, if the establishment of a joint venture (JV) with a local partner may lead to acquisition of the partner's stake in the future, the proper evaluation of the JV ex ante should take into account the economic impact of the possible acquisition later on. The strategic option perspective, therefore, is in essence dynamic.

The first study that applied the concept of strategic options to the analysis of market entry decisions is Kogut [1991]. Focusing on the uncertainty of market demand and the resolution of such uncertainty over time, Kogut suggested several conditions under which firms may set up JVs as strategic options to expand in case of receiving favorable market responses. In this paper, we will examine the necessity and sufficiency of some of these conditions for firms to form JVs as well as the implications of uncertainty about some other variables that are unrelated to market demand. A more recent study that empirically investigates market entry decisions under both the transaction cost and strategic option perspectives is Folta and Leiblein [1994]. It is our hope that the theoretical analysis of this paper will shed new light on the interactions between transaction cost and strategic option considerations to benefit future empirical studies.

The paper is organized as follows. The next section constructs a simple strategic option model on the choice between collaboration and going it alone in entering a new market. Section 3 explicates a necessary and sufficient condition for the option to acquire or sell out to be valuable to the partners of a JV. In section 4, an expanded model is developed to examine the interactions between transaction cost and strategic option considerations. Some of the empirical implications from our theoretical analyses are developed into testable hypotheses in section 5. The last section summarizes and concludes the paper. 
Chi, Tailan. (1996) Collaborative Ventures and Value of Learning: Integrating the Transaction Cost and Strategic Option Perspectives on the Choice of Market Entry Modes. Journal of International Business Studies, 27 (2), 285-307. Publisher's Official Version: http://www.jstor.org/stable/155286 Open Access Version: http://kuscholarworks.ku.edu/

\section{A STRATEGIC OPTION MODEL}

In this section, we develop a simple stochastic model to examine how the existence of certain strategic options might affect the choice between going it alone and collaborating with a partner in entering a new market. The model to be derived here is a two-stage binomial model based on the financial option pricing model introduced by Cox, Ross, and Rubinstein [1979]. The model takes a CV as the "base" mode, because this mode of operation generally is subject to more sources of uncertainty than a sole venture. A CV by definition may or may not involve shared equity ownership between the participants, although our discussion for the most part will be directed at equity JVs. We will first set up the model from the MNE's standpoint. The next section will take a game-theoretic approach and examine the conditions under which both the MNE and the local firm see the option to acquire the other as offering them an economic benefit.

An MNE that is contemplating collaboration with a local firm may encounter multiple sources of uncertainty that bear on its payoff from the project. First, the market demand for its product or service may have to be ascertained gradually from data on the venture's sales over a considerable period of time [Kogut 1991]. Second, although the MNE may expect to benefit from some complementary resources possessed by the local firm, an accurate assessment of the partner's capabilities may not be attainable without an extended period of joint operation with the firm [Chi 1994]. Furthermore, even if the local firm's ability is well known, there can still be a significant level of uncertainty about its effort in contributing the resources. If the contributions expected from the local firm contain a lot of tacit elements, the MNE can be expected to face difficulty in verifying its partner's true performance, and the knowledge of this situation may in turn induce the local firm to shirk its responsibility [Hennart 1988]. Since the MNE generally does not know for sure if the local firm will behave in an opportunistic manner or not, a level of uncertainty about its partner's effort is likely to exist and to be resolved through a period of collaboration between them. In addition, a period of joint operation may also enable the MNE to 
Chi, Tailan. (1996) Collaborative Ventures and Value of Learning: Integrating the Transaction Cost and Strategic Option Perspectives on the Choice of Market Entry Modes. Journal of International Business Studies, 27 (2), 285-307. Publisher's Official Version: http://www.jstor.org/stable/155286 Open Access Version: http://kuscholarworks.ku.edu/

learn more about the local firm's propensity to engage in other opportunistic behavior aimed at misappropriating earnings from the MNE's technology [Teece 1987].

The uncertainty about the above-mentioned factors necessarily renders the MNE's payoff from the $\mathrm{CV}$ uncertain when the $\mathrm{CV}$ is being negotiated. To aid our exposition, let $\tilde{x}$ denote the true value of the venture that is binomially distributed as either $x_{u}$ or $x_{d}$, with $x_{u}>x_{d}$, and assume that the MNE does not know whether $\tilde{x}=x_{u}$ or $\tilde{x}=x_{d}$ until sometime after the CV is formed. Given the two-stage framework of our model, we refer to the formation of the CV as stage 1 and the resolution of the uncertainty as stage $2 .{ }^{1}$ In addition, let $p$ represent the MNE's estimation of the probability for $x_{u}$ to occur, so that the probability for $x_{d}$ to occur can be simply denoted by $1-p$. Finally, we use $s(\geq 0, \leq 1)$ to denote the MNE's share of the CV's equity (the venture will be an equity $\mathrm{JV}$ if $0<s<1$ ) and use $I_{0}$ to denote the initial investment required by the project.

After the resolution of the uncertainty at stage 2, the MNE may find it advantageous to dissolve the CV by acquiring the local partner's interest in the venture or selling its own interest to the local partner. The price for the transfer of ownership interests between the two parties may be set in their original $\mathrm{CV}$ contract or negotiated after the establishment of the venture. In certain situations, the two partners may choose to specify the procedure for determining the share price, such as to accept the appraisal of an independent evaluator [Kogut 1991]. For the time being, we assume that the share price is set via negotiation as a multiple of $I_{0}$ in the initial CV contract and that the MNE holds both the options to acquire (a call option) and sell out (a put option) at the prescribed price. Under this assumption, the MNE has three alternatives at stage 2: acquire the shares held by the local firm, continue the $\mathrm{CV}$, or sell its own shares to the local firm. Then, the MNE's payoff at stage 2 is given by either of the following functions, depending on whether $x_{u}$ or $x_{d}$ turns out to be the true state of nature.

$$
\begin{aligned}
& v_{u}=\max \left[x_{u}-(1-s) a I_{0} ; s x_{u} ; s b I_{0}\right] \\
& v_{d}=\max \left[x_{d}-(1-s) a I_{0} ; s x_{d} ; s b I_{0}\right]
\end{aligned}
$$


Chi, Tailan. (1996) Collaborative Ventures and Value of Learning: Integrating the Transaction Cost and Strategic Option Perspectives on the Choice of Market Entry Modes. Journal of International Business Studies, 27 (2), 285-307. Publisher's Official Version: http://www.jstor.org/stable/155286 Open Access Version: http://kuscholarworks.ku.edu/

where $a$ and $b$ are parameters that affect the prices at which the MNE's options can be exercised. The functions defined in (1.1) and (1.2) presume that the MNE will choose the most profitable alternative after the state of nature is revealed. It can get $\tilde{x}-(1-s) a I_{0}$ by exercising the option to acquire, get $s \tilde{x}$ by staying in the $\mathrm{CV}$ and get $s b I_{0}$ by exercising the option to sell out.

It is convenient here to explain how the two parameters, $a$ and $b$, should be interpreted. The value of $a$ determines the cost that the MNE must incur to buy out its partner. We can think of $a$ as a function of two factors: one is the monetary price that the MNE must pay to acquire the shares held by the local firm, and the other is an additional cost or benefit that may accrue from the severance of the relationship. An extra cost that the MNE may incur after the acquisition can result from the loss of access to the local firm's complementary resources that the MNE failed to replicate during the period of collaboration. An extra benefit that the MNE may derive from the acquisition can be due to the prevention of more proprietary information being leaked to and possibly misused by the local firm. So, if the MNE could acquire its partner's shares at the cost of the initial investment $I_{0}$ and if there is no other cost or benefit in severing the relationship, $a$ would be equal to one. The value of $a$ can be viewed as an increasing function of the exercise price and any extra (net) costs for the acquisition.

The factors affecting $b$ are the opposite of those affecting $a$. So, the value of $b$ can be viewed as an increasing function of the exercise price and any other (net) benefits arising from selling out its shares to the local firm. In the case of a sell-out, any knowledge the MNE acquires from the local firm would be an extra benefit, although the value of such knowledge would be deducted from the exercise price if the knowledge transfer is anticipated by both parties in the initial negotiation of the option. Similarly, any anticipated knowledge transfer from the MNE to the local firm can be expected to increase the exercise price for such a sell-out. If $b$ is equal to one, the MNE would receive only the amount of its initial investment in the project.

Using the two functions defined in (1.1) and (1.2), the MNE's expected return from the venture in the presence of the embedded options can be expressed as 
Chi, Tailan. (1996) Collaborative Ventures and Value of Learning: Integrating the Transaction Cost and Strategic Option Perspectives on the Choice of Market Entry Modes. Journal of International Business Studies, 27 (2), 285-307. Publisher's Official Version: http://www.jstor.org/stable/155286 Open Access Version: http://kuscholarworks.ku.edu/

$$
V_{0}=\frac{p v_{u}+(1-p) v_{d}}{1+k}-s I_{0}-\theta
$$

where $k>0$ is the required rate of return (the discount rate) and $\theta \geq 0$ is a possible side payment that the MNE gives to the local firm for the provision of the options, which could cause the local firm to incur an economic cost. ${ }^{2}$ The term $s I_{0}$, with $0 \leq s \leq 1$, represents the initial investment of the MNE in the venture's equity. Following the tenets of financial economics, we assume that firms are only concerned about systematic risk and account for such risk by choosing a proper discount rate $(k)$ in project evaluation. The rationale for this assumption, as explained in standard finance models, is that stockholders can diversify away nonsystematic risks by themselves. ${ }^{3}$

The function defined in (2) can be used to examine a number of factors that influence the value of the options from the MNE's standpoint. The graph in the upper panel of Figure 1 shows how the MNE's expected return from the venture, $V_{0}$, varies with the difference between the two possible values of the venture's payoff, $\delta=x_{u}-x_{d}$, under a specific set of parameter values. ${ }^{4}$ It can be seen from the graph that $V_{0}$ is an increasing function of $\delta$. As $\delta$ measures the variability of the venture's uncertain payoff (the variance of $\tilde{x}$ is equal to $\delta^{2} / 16$ ), this parameter represents the extent of uncertainty and learning potential about the outcome of the venture from the MNE's perspective. The intuition behind the positive relationship between $V_{0}$ and $\delta$ is that the options held by the MNE enable it to exploit the uncertainty and learning potential to its own advantage. Under the assumption of $a I_{0}=b I_{0}=\bar{x}$ in the numerical example of Figure 1, the MNE will always come out ahead by exercising one of the options unless $\delta=0$, in which case the options have no value since the exercise price is identically equal to the value of the project (i.e., $I_{0}=x_{u}=x_{d}$ ).

\footnotetext{
$* * * * * * * * * * * * * * * *$

Put Figure 1 here

$* * * * * * * * * * * * * * * *$
}

It is easy to see that, if an option embedded in a CV is not available in a sole venture, then the option necessarily gives the $\mathrm{CV}$ an advantage over going it alone. ${ }^{5}$ Using the same parameter values assumed in the numerical example of Figure 1, the MNE's expected payoff from going it alone can be calculated as 
Chi, Tailan. (1996) Collaborative Ventures and Value of Learning: Integrating the Transaction Cost and Strategic Option Perspectives on the Choice of Market Entry Modes. Journal of International Business Studies, 27 (2), 285-307. Publisher's Official Version: http://www.jstor.org/stable/155286 Open Access Version: http://kuscholarworks.ku.edu/

$$
\bar{V}_{0}=\frac{\bar{x}}{1+k}-I_{0}=\frac{1.0}{1.1}-1=-0.0909
$$

The difference between $s \bar{V}_{0}=-0.9090 s$ and the MNE's expected payoff from the CV gives the value of the options embedded in the CV. This example clearly illustrates that the embedding of strategic options in a particular mode of operation can alter the MNE's assessment of different market entry modes. The value of such options is a rising function of the uncertainty involved because greater uncertainty increases the value of being able to incorporate any newly gathered information into managerial decisions. It is not the uncertainty per se, but rather the potential for improving decisions on the basis of new information gathered, that makes the options valuable. ${ }^{6}$

The lower panel of Figure 1 plots the MNE's expected return against its equity share in the $\mathrm{CV}$ when it can only exercise one of the two options at a prespecified price. As can be seen from the graph, the MNE's expected return is a decreasing (increasing) function of its equity share when its holds only an option to acquire (sell out). The intuition behind these relationships can be explained as follows. Since the option to acquire at a fixed price enables the option holder to take advantage of the venture's upward potential, a smaller initial share reduces its exposure to the venture's downward risk while still allowing it to benefit fully from the venture's upward potential. On the other hand, since the option to sell out at a fixed price enables the option holder to cover the venture's downward risk, a larger initial share allows it to benefit more fully from the venture's upward potential while still covering its exposure to the venture's downward risk. This result suggests that a $\mathrm{CV}$ partner holding only an option to acquire (sell out) will prefer its equity share to be as low (high) as possible when everything else is held constant. In fact, the option to acquire (sell out) becomes irrelevant to a party that holds $100 \%(0 \%)$ of the ownership to a venture. Given that $100 \%$ ownership represents a sole venture and $0 \%$ ownership represents a collaborative venture without equity ownership, our preceding analysis also shows how optionrelated considerations may influence a firm's assessment of different market entry modes. ${ }^{7}$ 
Chi, Tailan. (1996) Collaborative Ventures and Value of Learning: Integrating the Transaction Cost and Strategic Option Perspectives on the Choice of Market Entry Modes. Journal of International Business Studies, 27 (2), 285-307. Publisher's Official Version: http://www.jstor.org/stable/155286 Open Access Version: http://kuscholarworks.ku.edu/

\section{A CONDITION FOR JOINT VENTURES TO POSSESS VALUED OPTIONS}

We have demonstrated in the preceding section that an MNE participating in an equity JV will value the right to acquire its partner's interest or sell out its own interest to the partner at a predetermined price when the payoff from the JV is uncertain. But an important question that we have not yet answered is: Under what conditions would the two parties find it mutually beneficial to have such option clauses in their JV agreement? Or more generally, under what conditions would they derive any economic value from having the option to acquire the other's interest, with or without a prespecified price? Our goal in this section is to explore the answers to these questions, using an extension of the model constructed in the previous section. In order to analyse the problem from the perspectives of both parties, we will treat the JV process as a two-stage game where the JV contract is negotiated in the first stage and implemented in the second stage. The fundamental presumption of such a game-theoretic approach is that each party chooses its moves to maximize its expected gains and anticipates its opponent also to follow this type of selfpreserving behavior in each and every stage of the game [Harsanyi and Selten 1988].

As pointed out earlier, the local firm takes on obligations that can carry an economic cost when it agrees to give the MNE the option to acquire or sell out the JV at a predetermined price. What is then the exact economic cost that the local firm may incur in this kind of arrangement? If the two parties are expected to agree ex post on the evaluation of the possible states of nature, $x_{u}$ and $x_{d}$, then the payoff of the local firm under each state will be either of the following.

$$
\begin{aligned}
& w_{u}=\lambda_{u}^{a}(1-s) a I_{0}+\lambda_{u}^{n}(1-s) x_{u}+\lambda_{u}^{b}\left[x_{u}-b s I_{0}\right] \\
& w_{d}=\lambda_{d}^{a}(1-s) a I_{0}+\lambda_{d}^{n}(1-s) x_{d}+\lambda_{d}^{b}\left[x_{d}-b s I_{0}\right]
\end{aligned}
$$

where $\lambda_{i}^{j}=1,0$ indicates whether the MNE's decision at stage 2 is to acquire the local firm's shares $\left(\lambda_{i}^{a}=1\right)$, stay in the JV $\left(\lambda_{i}^{n}=1\right)$, or sell out its own shares $\left(\lambda_{i}^{b}=1\right)$. So the local firm's expected payoff as of stage 1 can be expressed as

$$
W_{0}=\frac{p w_{u}+(1-p) w_{d}}{1+k}-(1-s) I_{0}+\theta
$$


Chi, Tailan. (1996) Collaborative Ventures and Value of Learning: Integrating the Transaction Cost and Strategic Option Perspectives on the Choice of Market Entry Modes. Journal of International Business Studies, 27 (2), 285-307. Publisher's Official Version: http://www.jstor.org/stable/155286 Open Access Version: http://kuscholarworks.ku.edu/

\section{$* * * * * * * * * * * * * * * *$ \\ Put Figure 2 here \\ $* * * * * * * * * * * * * * * *$}

The graphs in Figure 2 illustrate how the expected payoffs of the two parties would vary with changes in the relative share of the two parties $(s)$ and in the premium $(\theta)$ that the MNE pays the local firm for the options to acquire or sell out at pre-negotiated prices. It can be easily seen from the graphs that the expected payoffs of the two parties always sum to zero under such an arrangement. $^{8}$ This result suggests that giving one of the parties the option to acquire or sell out at a prespecified price creates no economic value for the two parties when they are expected to have the same ex post valuation of the venture. The reason is that under these conditions the MNE's gain from exercising either option at stage 2 necessarily equals the local firm's loss. This reasoning also applies to the case where no exercise price is set in the contract, because the negotiation of the acquisition price at stage 2 is necessarily a zero-sum game when they have the same valuation of the shares to be transacted under each state of nature.

Now let us modify the assumptions of our model as follows: although each party's ex post valuation of the venture is still either $x_{u}$ or $x_{d}$ with a 50-50 chance, they may view the realized state differently at stage 2 . For simplicity, suppose that their ex post valuations are identically and independently distributed; that is, there is a $50 \%$ chance that the value of the venture is $x_{u}$ to one of them and is $x_{d}$ to the other and a $50 \%$ chance that both of them view the venture's value as $x_{u}$ or $x_{d}$. This set of conditions can arise if the venture may turn out to have greater synergy with one of the firms than with the other but neither of them is sure ex ante what the actual result will be. ${ }^{9}$ If the two parties happen to have divergent valuations of the venture at stage 2 , then the party that values the venture more will have an incentive to buy out the other at a price between $0.01 x_{u}$ and $0.01 x_{d}$ for each percent of the JV's equity. If the two parties happen to have the same valuation of the venture at stage 2 , however, the only feasible price for the transfer of the JV's shares between them is their identical valuation. For the ease of exposition, suppose that each party initially owns $50 \%$ of the JV's equity and that any share transfer between them at stage 2 is 
Chi, Tailan. (1996) Collaborative Ventures and Value of Learning: Integrating the Transaction Cost and Strategic Option Perspectives on the Choice of Market Entry Modes. Journal of International Business Studies, 27 (2), 285-307. Publisher's Official Version: http://www.jstor.org/stable/155286 Open Access Version: http://kuscholarworks.ku.edu/

to occur at the midpoint between $x_{u}$ and $x_{d}$, that is, $\bar{x}=\left(x_{u}+x_{d}\right) / 2$. We can consider this acquisition price as either set in the original JV contract or negotiated after the state of nature is revealed. Then, when they have divergent evaluations, the party that values the venture more and acquires all of the venture's shares receives $x_{u}-0.5 \bar{x}$ while the other party receives $0.5 \bar{x}$. Given the symmetry between the two parties under our simplifying assumptions, the expected payoff of each party at stage 1 will be exactly the same and can be written as follows. ${ }^{10}$

$$
V_{0}=\frac{0.25\left[0.5 x_{u}+0.5 x_{d}+\left(x_{u}-0.5 \bar{x}\right)+0.5 \bar{x}\right]}{1+k}-0.5 I_{0}
$$

The first two terms in the brackets represent their payoffs when they have identical valuations of the venture; while the last two terms in the brackets represent their payoffs from, respectively, acquiring and selling out to their partner. Note that their expected payoff from going it alone is

$$
\bar{V}_{0}=\frac{\bar{x}}{1+k}-I_{0}
$$

$* * * * * * * * * * * * * * * *$

Put Table 1 here

$* * * * * * * * * * * * * * * *$

Table 1 shows how the difference between these two functions, $V_{0}-\bar{V}_{0}$, is influenced by the mean and variance of the probability distribution of the venture's potential values, $x_{u}$ and $x_{d}$. Note that $V_{0}-\bar{V}_{0}$ reflects the value of the strategic options embedded in the JV and that for both parties joint venturing will be more advantageous than going it alone unless $V_{0}-\bar{V}_{0}<0$. It can be seen from the table that a JV becomes a more favorable mode of market entry as the expectation of the venture's possible values is lower or as the two possible values are more widely dispersed. The negative relationship between $V_{0}-\bar{V}_{0}$ and $\bar{x}$ is due to risk sharing in the JV, which reduces a party's loss in a bad state of nature $\left(x_{d}\right)$ as well as its gain in a good state of nature $\left(x_{u}\right)$. Since a rise in the value of $\bar{x}$ increases the gain from the good state and decreases the loss from the bad state, it reduces the benefit from risk sharing in a JV. The positive relationship between $V_{0}-\bar{V}_{0}$ and $\delta$ is due to the options embedded in the $\mathrm{JV}$, because the option to acquire or sell out allows the two parties to exploit the uncertainty about the extent of synergy that may exist between the 
Chi, Tailan. (1996) Collaborative Ventures and Value of Learning: Integrating the Transaction Cost and Strategic Option Perspectives on the Choice of Market Entry Modes. Journal of International Business Studies, 27 (2), 285-307. Publisher's Official Version: http://www.jstor.org/stable/155286 Open Access Version: http://kuscholarworks.ku.edu/

JV and each party's other operations. It is interesting to note that in this numerical model a sole venture becomes superior only when the expected value of the venture is unusually large -7 to 8 times greater than the initial investment $I_{0}$.

The above analysis reveals a necessary and sufficient condition for the option to acquire or sell out in a JV to provide a positive economic value for its partners; this condition is that the partners anticipate a possible divergence between their ex post valuations of the JV. As suggested earlier, the divergence of their valuations can be due to differing degrees of synergy between the JV and the separate operations of the two parties. Kogut [1991] observed that the reason for a JV partner to buy out the other is likely to be the existence of a difference between their ex post evaluations of the JV's assets. Our preceding analysis suggests that their ex ante anticipation of the possibility of such ex post differences can by itself be one of the motives for their going into a $\mathrm{JV}$ in the first place.

It is useful to distinguish the ex post asymmetry discussed above from what can be called ex ante asymmetry between the JV partners. Although the numerical example given by function (6) allows asymmetric valuations of the venture ex post, it presumes the two parties to have the same probability assessments regarding the possible outcomes of the venture. Since under such $e x$ ante symmetry the two parties benefit equally from the option to acquire or sell out, there is no reason to designate only one of them as the holder of the option in their JV contract. So, in order for them to see a benefit from "trading" such option rights in the negotiation of their JV contract, there must exist some ex ante asymmetry that causes one of them to value the option more than the other does. Such ex ante asymmetry can arise from the condition that one of the parties does not foresee much chance for it to value the venture more than its partner does. ${ }^{11}$ It can also arise when the two parties anticipate to have differing abilities to absorb their partner's proprietary knowledge or when they experience differing levels of uncertainty about the venture's outcome. In the next section, we will explore a number of transaction cost related factors that can give rise to various asymmetries between the JV partners both ex ante and ex post. 
Chi, Tailan. (1996) Collaborative Ventures and Value of Learning: Integrating the Transaction Cost and Strategic Option Perspectives on the Choice of Market Entry Modes. Journal of International Business Studies, 27 (2), 285-307. Publisher's Official Version: http://www.jstor.org/stable/155286 Open Access Version: http://kuscholarworks.ku.edu/

\section{STRATEGIC OPTIONS AND TRANSACTION COST PROBLEMS}

This section is divided into two parts. The first part analyzes the option property of CVs in reducing the risk of misappropriation, and the second part analyzes the option property of CVs in reducing information asymmetry between the two partners. A slightly more complex model is constructed to examine the issues raised by both parts of the section.

\section{Misappropriation Risk}

The main risk that the MNE faces in collaborating with a local firm is the possibility of the local firm absorbing and misappropriating the rents from its proprietary knowledge due to imperfections in the prevailing legal system governing industrial property rights [Hennart 1982; Stopford and Wells 1972]. Such misappropriation can, but does not have to, result from the local firm's breach of some explicit or implicit contractual agreement. The MNE may simply fail to foresee certain improvements of its knowledge and leave it open for the first discoverer of these improvements to appropriate the earnings from them. Since the risk of misappropriation has both technological and behavioral roots, the size of the risk is largely determined by two uncertain variables. One concerns the nature and extent of possible future improvements on the current knowledge [Hill 1992]; and the other concerns the opportunistic tendency of the partner, given that some economic agents may be more prone to opportunism than others [Williamson 1975].

Although the MNE is likely to get additional information about both of these uncertain variables, such new information may or may not affect its assessment of the $\mathrm{CV}$ as the ongoing mode of operation. After a set of knowledge is revealed to the local firm, there may be little that the MNE can do to alter the chance of and loss from misappropriation, no matter how much future potential its knowledge is found to have, or how untrustworthy the local firm turns out to be. So whenever there is a chance of revealing to the local firm (intentionally or unintentionally) any knowledge that cannot be perfectly protected, the MNE incurs an expected sunk cost from the beginning. We use $c$ to denote this expected sunk cost. 
Chi, Tailan. (1996) Collaborative Ventures and Value of Learning: Integrating the Transaction Cost and Strategic Option Perspectives on the Choice of Market Entry Modes. Journal of International Business Studies, 27 (2), 285-307. Publisher's Official Version: http://www.jstor.org/stable/155286 Open Access Version: http://kuscholarworks.ku.edu/

However, since technological and managerial know-how often has a lot of tacit elements [Teece 1982], the amount of knowledge that the local firm is able to acquire from the MNE in a given period of collaboration is likely to be uncertain. So far as the MNE foresees a chance to withhold some of its proprietary knowledge from the local firm, new information about its knowledge's potential or its partner's behavior could change the MNE's decision on whether to continue the CV. Since this type of new information primarily affects how large a benefit or cost there will be if the $\mathrm{CV}$ is dissolved, the effect of such uncertainty can be analyzed by introducing another stochastic variable $\tilde{y}$ to represent this extra benefit $(\tilde{y}>0)$ or cost $(\tilde{y}<0)$ in our model. In accordance with our two-stage binomial framework, we assume that the realized value of $\tilde{y}$ is either $y_{l}$ or $y_{h}$, with $y_{l}<y_{h}$, and that the two random variables $\tilde{x}$ and $\tilde{y}$ are independently distributed. Let $q$ represent the probability for $y_{l}$ to occur so that the probability for $y_{h}$ to occur can be denoted by $1-q$. As the addition of this second binomial variable raises the number of possible states of nature from two to four, the MNE's payoff at stage 2 is given by one of the following functions.

$$
\begin{aligned}
v_{u}^{l} & =\max \left[x_{u}-(1-s) a I_{0}+y_{l} ; s x_{u} ; s b I_{0}+y_{l}\right] \\
v_{u}^{h} & =\max \left[x_{u}-(1-s) a I_{0}+y_{h} ; s x_{u} ; s b I_{0}+y_{h}\right] \\
v_{d}^{l} & =\max \left[x_{d}-(1-s) a I_{0}+y_{l} ; s x_{d} ; s b I_{0}+y_{l}\right] \\
v_{d}^{h} & =\max \left[x_{d}-(1-s) a I_{0}+y_{h} ; s x_{d} ; s b I_{0}+y_{h}\right]
\end{aligned}
$$

Incorporating also the expected sunk cost $c$ in the model, the MNE's expected return at stage 1 can now be expressed as ${ }^{12}$

$$
V_{0}=\frac{p q v_{u}^{l}+p(1-q) v_{u}^{h}+(1-p) q v_{d}^{l}+(1-p)(1-q) v_{d}^{h}}{1+k}-s I_{0}-c-\theta
$$

Note that the parameter $c$ represents an expected sunk cost of potential misappropriation by the local firm of the MNE's proprietary knowledge revealed in the collaboration process. It was mentioned in the preceding section that the formation of a CV could also cause the MNE to lose certain options. The effect of the parameter $c$, which can be easily seen to reduce the value of $V_{0}$ and thus increase the advantage of a sole venture, illustrates this point. The option lost here is 
Chi, Tailan. (1996) Collaborative Ventures and Value of Learning: Integrating the Transaction Cost and Strategic Option Perspectives on the Choice of Market Entry Modes. Journal of International Business Studies, 27 (2), 285-307. Publisher's Official Version: http://www.jstor.org/stable/155286 Open Access Version: http://kuscholarworks.ku.edu/

the option to retain all of its proprietary knowledge. Also note that due to the presence of $y_{l}$ and $y_{h}$ in $V_{0}$, as defined by (8) and (9), the MNE will have a different evaluation of the CV than the local firm unless $y_{l}=y_{h}=0$.

As alluded to earlier, by dissolving the $\mathrm{CV}$ at stage 2, the MNE can obtain a benefit due to the prevention of more knowledge being leaked to the local firm and can also incur a cost due to the loss of access to the local firm's complementary resources. Given that the difference between $y_{l}$ and $y_{h}$ represents the extent of uncertainty about such benefits and costs, the effect of changes in $\Delta=y_{h}-y_{l}$ on the value of $V_{0}$ indicates how uncertainty with regard to the problem of misappropriation affects the choice of market entry modes. The graph in Figure 3 shows the relationship between $\Delta$ and $V_{0}$ as defined in (8) and (9). Their positive relationship suggests that uncertainty about the hazards of transaction cost problems can also increase the advantage of a $\mathrm{CV}$. It should, however, be stated very clearly that this advantage is due to the potential for gaining new information on the partner's behavioral tendency in the initial stage of collaboration while keeping down the exposure of one's proprietary knowledge to the partner. This type of learning is perhaps a very important part of what practitioners often call "trust building" in a world where economic agents follow divergent behavioral norms and cannot easily ascertain what norms are being followed by other agents due to the disguise that some of them try to wear.

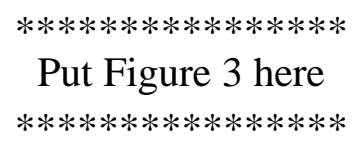

Put Figure 3 here

$* * * * * * * * * * * * * * * *$

\section{Information Asymmetry}

A number of authors have suggested that a JV may be preferred to an outright acquisition when there exists a significant degree of information asymmetry between the potential buyer and seller of a productive asset [Balakrishnan and Koza 1993; Hennart 1988; Shan 1990]. Problems of information asymmetry can be characterized as either adverse selection or moral hazard [Holmstrom 1982]. Adverse selection arises from the condition that the potential buyer of the asset knows less about the quality of the asset than the seller and can create severe difficulty in the 
Chi, Tailan. (1996) Collaborative Ventures and Value of Learning: Integrating the Transaction Cost and Strategic Option Perspectives on the Choice of Market Entry Modes. Journal of International Business Studies, 27 (2), 285-307. Publisher's Official Version: http://www.jstor.org/stable/155286 Open Access Version: http://kuscholarworks.ku.edu/

negotiation between the two parties on the price of the asset [Akerloff 1970]. Moral hazard can arise in the sale of a productive asset (such as a new technology) when a proper transfer of the asset requires the seller to make a costly effort of training that is difficult for the buyer to monitor [Teece 1982]. Although existing literature has thoroughly explicated the rationale for a JV to reduce the negative impact of information asymmetry in a static setting, few studies have examined how the potential for learning under this type of uncertainty may affect the economic viability and structural design of JVs. ${ }^{13}$ The objective of this subsection is to explore some of the dynamic issues in joint venturing under conditions of information asymmetry.

Balakrishnan and Koza [1993] observed that the potential buyer of an asset could use a JV with the current owner of the asset to gather more information about its value when there is a significant level of information asymmetry between the two parties. Although they did not make the connection explicit in their article, their observation is clearly related to the strategic option concept. When the asset being traded consists primarily of tacit production knowledge, the exchange is likely to be plagued by both adverse selection and moral hazard [Chi 1994]. Since a complete transfer of such knowledge requires the seller to make a costly effort of training that is difficult for the buyer to monitor, the extent of uncertainty that faces the buyer in the beginning can be greatly exacerbated. Much of this initial uncertainty, however, is likely to be resolved over time as more and more of the knowledge is revealed and transferred. This gradual reduction of uncertainty can make a JV with an acquisition option an effective mechanism for alleviating both adverse selection and moral hazard.

A remedy for the combined adverse selection and moral hazard problem requires two essential elements: one is sufficient incentive for the seller to provide the requisite training, and the other is alleviation of the buyer's concern about overpayment. A JV with an option to acquire can contain both elements. First, by giving the seller a high initial share of the venture's equity, a JV can let the seller be paid primarily out of the profit from the venture until the buyer exercises the option to acquire. As such an arrangement makes the buyer's payment of the acquisition price 
Chi, Tailan. (1996) Collaborative Ventures and Value of Learning: Integrating the Transaction Cost and Strategic Option Perspectives on the Choice of Market Entry Modes. Journal of International Business Studies, 27 (2), 285-307. Publisher's Official Version: http://www.jstor.org/stable/155286 Open Access Version: http://kuscholarworks.ku.edu/

contingent on the completion of the knowledge transfer, it can give the seller a potentially strong incentive to provide the requisite training for the buyer. Since a higher equity share by the seller necessarily means that the buyer makes a smaller equity investment in the beginning, the buyer's exposure to the risk of overpayment is also reduced. In addition, because the buyer is not bound to acquire the venture if the knowledge transfer is unsatisfactory, the option arrangement can also reduce excessive bargaining over the acquisition price in their initial negotiation.

It should be noted, however, that the option arrangement described above does not preclude the buyer from renegotiating the acquisition price or withdrawing from the JV without adequate payment for what it has learnt from the seller. Hence, the economic viability of the arrangement as a remedy for the information asymmetry problem can be undermined by the misappropriation risk involved. Since the risk primarily affects assets that are embodied in information (technology and know-how) and thus can be used by two or more parties simultaneously [Casson 1979], the viability of the arrangement should be high when the assets being traded are primarily physical in nature. In addition, although existing patent and contract laws also provide some protection for owners of proprietary knowledge, the extent of protection can vary significantly with the nature of the knowledge [Hennart 1982; Teece 1987]. The viability of the arrangement, therefore, can be expected to fall as the knowledge involved receives less adequate protection under the prevailing legal system.

The above analysis has empirical implications with regard to which party is likely to hold an option to acquire the other's ownership interest in a JV when the JV potentially involves the transfer of some proprietary technology from the MNE to the local firm. As suggested earlier in this section, by limiting the scale and scope of technology transfer in the beginning, the MNE can use the JV to assess the local firm's capabilities and behavioral tendencies before it undertakes any major effort in technology transfer. Since the MNE is likely to attach a greater value to the right to acquire the venture when its technology is more vulnerable to misappropriation, we can expect that the MNE is more likely to demand such a right rather than give it to the local firm when its 
Chi, Tailan. (1996) Collaborative Ventures and Value of Learning: Integrating the Transaction Cost and Strategic Option Perspectives on the Choice of Market Entry Modes. Journal of International Business Studies, 27 (2), 285-307. Publisher's Official Version: http://www.jstor.org/stable/155286 Open Access Version: http://kuscholarworks.ku.edu/

technology is less easily protected. If existing patent and contract laws do provide the MNE with relatively adequate protection against potential misappropriation of its technology, however, we can expect a higher likelihood that the JV is formed to facilitate the transfer of the technology to the local firm. Since giving the local firm the option to acquire the venture can alleviate the potential buyer uncertainty problem it faces, we can expect that the local firm is more likely to hold an option to acquire the venture under such conditions. Given that the uncertainty in either case affects how much the option holder can gain or lose from acquiring the venture from its partner, the model constructed earlier in this section can be used to assess the value of joint venturing for both parties. As demonstrated in the numerical example of Figure 3, the value of the option is greater as the option holder experiences higher uncertainty. ${ }^{14}$

\section{EMPIRICAL IMPLICATIONS FOR THE STRUCTURING OF JOINT VENTURES}

The purpose of this section is to develop the theoretical results of the preceding sections into some testable hypotheses concerning the contracting structure of JVs. As the hypotheses pay particular attention to JVs that give one of the parties the right to acquire the other's ownership interest at a prespecified price, we first identify the conditions under which the JV partners can be expected to find such a contractual arrangement mutually beneficial.

As suggested earlier, the extent of uncertainty facing the two parties is the highest before the start of their JV, and is likely to decline over time as their joint undertaking progresses. Given that negotiation tends to be more difficult when there is greater uncertainty, what would motivate the two parties to set the acquisition price in their initial contract rather than negotiating it later, when much of the initial uncertainty is resolved? The answer seems to lie in their anticipation of a possible change in their relative bargaining power. If neither of them expect their bargaining power to change in the course of their collaboration, it would clearly be more efficient for them to negotiate the price later when the need arises. But as suggested by Beamish and Banks [1987], the transfer of production knowledge between JV partners is likely to result in a change of their relative bargaining power. So, if one of the parties expects its own bargaining power to weaken in 
Chi, Tailan. (1996) Collaborative Ventures and Value of Learning: Integrating the Transaction Cost and Strategic Option Perspectives on the Choice of Market Entry Modes. Journal of International Business Studies, 27 (2), 285-307. Publisher's Official Version: http://www.jstor.org/stable/155286 Open Access Version: http://kuscholarworks.ku.edu/

the course of the JV, it would be motivated to negotiate the acquisition price early on, and put pressure on the other party to do so (e.g., by threatening not to enter into a JV).

Hence, based on our analyses in the preceding paragraph and in sections 2 and 3, we can attribute the motivation for such an option clause to a combination of three conditions. The first is the existence of uncertainty and learning potential about the value that a party can realize from acquiring the venture from its partner in the foreseeable future. Without this condition, the option would have little value. The second is the anticipation of a shift in the bargaining power of the two partners in the course of their collaboration. As alluded to above, this condition motivates the parties to set the acquisition price in their initial contract. The third is the existence of some ex ante asymmetry in their expected gains from acquiring the JV. This condition motivates the identification of the option holder, since the asymmetry between them makes it beneficial for them to trade in the right to the option. It is conceivable that each of these conditions is present to some extent in nearly every JV. Then, whether the partners of a JV find it justifiable to insert an option-to-acquire clause in their JV contract will depend on the strengths of these conditions. We therefore can expect that a strengthening of any of the conditions will increase the likelihood for the JV partners to make such an option arrangement.

\section{Market Uncertainty vs. Partner Uncertainty}

Our analysis in section 2 identified two important sources of uncertainty in a JV: one is uncertainty about the market and the other is uncertainty about the partner (regarding its ability or behavioral tendency). Since the value of any option is an increasing function of the uncertainty about its underlying asset, we expect that a significant increase in each of these uncertainties will lead to a higher chance that the JV partners will install an explicit option clause in their initial contract. Generally, there is higher market uncertainty when the product of the JV is new to the local market, and there is higher partner uncertainty when the two parties have not had any prior collaborative experience with each other. Thus, we propose the following hypothesis about the incidence of an option-to-acquire clause in a JV agreement between an MNE and a local firm. 
Chi, Tailan. (1996) Collaborative Ventures and Value of Learning: Integrating the Transaction Cost and Strategic Option Perspectives on the Choice of Market Entry Modes. Journal of International Business Studies, 27 (2), 285-307. Publisher's Official Version: http://www.jstor.org/stable/155286 Open Access Version: http://kuscholarworks.ku.edu/

H1: A JV is more likely to contain an option-to-acquire clause ceteris paribus if its product is new to the local market or if its two partners have had no prior collaborative experience with each other.

This hypothesis can be tested using a binomial logit or probit model. The relative effect sizes of the two independent variables can provide an indication about the influence of market uncertainty relative to that of partner uncertainty on the structuring of JVs.

\section{Designation of Option Holder}

We have in the preceding section suggested a condition that can help predict which party is likely to hold an option to acquire the other's ownership interest in situations where an MNE with certain proprietary technology joint ventures with a local firm. This condition, as explained earlier, is whether the MNE's technology receives adequate protection under the prevailing legal regime. Based on our analysis in the last section, we propose the following hypothesis.

$\mathrm{H} 2$ : The MNE (local firm) is more likely to hold an option to acquire the venture ceteris paribus when the prevailing legal regime is less (more) adequate in protecting MNE from potential misappropriation of its technology.

This hypothesis entails a trinomial dependent variable to indicate not only whether the JV contract contains an option-to-acquire clause but also which partner holds the option in case there is such an option clause. Unfortunately, we are not aware of a good objective measure of the extent of protection for various kinds of technology under a given legal regime. A test of the hypothesis may have to utilize a subjective measure based on the perception of the MNE's managers. A multinomial logit or probit model can be employed to perform the test.

\section{Apportionment of Equity Share}

Equity sharing in JVs has been explained as a mechanism for balancing the incentives of the partners when both of them are expected to make certain resource contributions that the other finds difficult to measure and monitor [Gomes-Casseres 1989; Hennart 1988; Shan 1990]. In the context of a JV between an MNE and a local firm, such hard-to-measure resource contributions 
Chi, Tailan. (1996) Collaborative Ventures and Value of Learning: Integrating the Transaction Cost and Strategic Option Perspectives on the Choice of Market Entry Modes. Journal of International Business Studies, 27 (2), 285-307. Publisher's Official Version: http://www.jstor.org/stable/155286 Open Access Version: http://kuscholarworks.ku.edu/

can be production know-how, marketing expertise, or knowledge on how to deal with the local government bureaucracy. Several transaction cost based models have suggested that a party's relative ownership share may be influenced by how much the venture's outcome depends on the hard-to-measure inputs expected from that party [Barzel and Suen 1988; Chi 1996; Eswaran and Kotwal 1985]. As our analysis in section 2 has demonstrated, however, the party that holds an option to acquire its partner's share at a fixed price is likely to prefer a smaller equity share for itself in order to exploit more fully the potential benefit from the option it holds. Then, the party holding such an option can be expected to bargain for a smaller share by making concessions to its partner in other areas. We therefore have the following hypothesis.

H3: A JV partner is likely to have a lower equity share ceteris paribus when it holds an option to acquire the other's ownership stake at a predetermined price than if it does not hold such an option.

A test of this hypothesis can be performed using a multiple regression model. The result can provide an indication of how strategic option considerations might alter the structure of JVs from what is predicted on the basis of transaction cost considerations alone.

\section{CONCLUSION}

In this paper, we developed a framework for integrating the transaction cost and strategic option perspectives on collaborative ventures. The main contribution of the framework is that it allows a dynamic assessment of CVs and the transaction cost problems to which they may be subject. Although the exploitation of interfirm synergy may be the primary and ultimate goal of any $\mathrm{CV}$, our analysis suggests that the initial stage of a $\mathrm{CV}$ can be viewed as a vehicle for learning more about the partner for future expansion of the collaboration or acquisition of the partner's stake. This learning potential combined with the options embedded in the CV enhances the economic value of collaborative venturing and thus can alter an MNE's choice between collaboration and going it alone (which precludes the exploration of potential synergy with a local firm). 
Chi, Tailan. (1996) Collaborative Ventures and Value of Learning: Integrating the Transaction Cost and Strategic Option Perspectives on the Choice of Market Entry Modes. Journal of International Business Studies, 27 (2), 285-307. Publisher's Official Version: http://www.jstor.org/stable/155286 Open Access Version: http://kuscholarworks.ku.edu/

Using a simple stochastic model, we explicated a condition that determines whether the option to acquire or sell out provides an economic value for the partners of a JV. Our model showed that such an option adds to the value of joint venturing whenever the JV partners foresee a possibility that they might have differing valuations of the venture ex post. In addition, we also suggested that the existence of certain ex ante asymmetry between the partners of a JV can motivate them to trade in the right to the option and that such asymmetry can often be traced to the presence of transaction cost problems. Using an expanded model that allows two sources of uncertainty, we demonstrated that the option to acquire and sell out can serve to reduce the risk of misappropriation and alleviate the difficulty of contracting under information asymmetry, thus adding to the value of collaborative venturing. Our analysis also suggested a condition that can help distinguish empirically which JV partner is likely to hold an option to acquire the other.

Based on our theoretical analyses, we derived three testable hypotheses, which we hope will lead to more rigorous empirical studies under a combined strategic option and transaction cost framework. It should also be noted that, although the theoretical insights and empirical implications of our paper have been derived in the context of a CV between an MNE and a local firm, most of them apply to any collaborative arrangements with or without the international dimension. $^{15}$ 
Chi, Tailan. (1996) Collaborative Ventures and Value of Learning: Integrating the Transaction Cost and Strategic Option Perspectives on the Choice of Market Entry Modes. Journal of International Business Studies, 27 (2), 285-307. Publisher's Official Version: http://www.jstor.org/stable/155286 Open Access Version: http://kuscholarworks.ku.edu/

\section{NOTES}

${ }^{1}$ Although an extension of our model to the case of continuous probability and continuous time may give a more accurate representation of reality under many circumstances, such an extension will greatly increase the model's mathematical complexity without altering its basic theoretical insights. One can easily extend the model to a multi-stage binomial model that has been shown to provide an accurate approximation of option models built under the assumption of continuous distribution and continuous time [Kamrad and Ritchken 1991; Trigeorgis 1991, 1993].

${ }^{2}$ In the parlance of financial options, $\theta$ represents the option premia. Here, we have made the simplifying assumption that the premia for the call and put options are the same per share. It should be noted that the two parties rarely need to be explicit about how a party is compensated for the provision of an option in their CV contract because they can easily make such a payment implicitly as a concession in their initial contract negotiation.

${ }^{3}$ Cox, Ross, and Rubinstein [1979] have shown that in a binomial stochastic model one can use the risk-free rate in lieu of the firm-specific discount rate by properly transforming the probability distribution of the two uncertain outcomes. The transformation requires the assumption that the risk of the asset underlying the option can be completely hedged using a portfolio of assets that are traded in the market. Such a transformation is not performed in our model because it does not add to the insights of our paper.

${ }^{4}$ For the ease of comparison, the numerical examples in our paper are constructed on a unit scale. In the example of Figure 1, for instance, we have assumed $a=b=I_{0}=\bar{x}=\left(x_{u}+x_{d}\right) / 2=1$.

${ }^{5}$ The formation of a CV can also cause the MNE to lose certain valuable options. This issue will be discussed later in the paper.

${ }^{6}$ Recent studies in financial economics suggest that the discovery of a stock's true value through observation of market variables will become less effective as those variables have a high noise-tosignal ratio due to the influence of uninformed speculators on the market [De Long, Shleifer, Summers and Waldmann 1992; Leach and Madhavan 1992]. In the context of our paper, there can also be noise in the sales figures of a JV, especially if its product is traded on an market that involves uninformed speculators. However, because the JV partners can engage in a lot of active learning, it seems reasonable to expect them to obtain more reliable information about the market and about each other after a sufficient length of time elapses.

${ }^{7} \mathrm{We}$ are indebted to an anonymous reviewer for suggesting this insight.

${ }^{8}$ Note that this result is derived under the assumption that the parties are not concerned about the nonsystematic risk involved in the project. Even if the JV partners do care about such risk and are risk averse, the option to acquire or sell out will not add any value to the venture unless there exists some other type of asymmetry. Such asymmetry can arise when one of the parties is more risk-averse or perceives greater risk than the other. Under this type of asymmetry, the party that is more risk-averse or perceives greater risk will value the option more than the other does and then be willing to purchase the option at a price that the other finds attractive (assuming they do care about nonsystematic risk). We are grateful to an anonymous reviewer for clarifying this point. ${ }^{9}$ For instance, IBM and Apple jointly formed Taligent (later also joined by Hewlett-Packard) to develop a new operating system for their next generation of personal computers. But the actual product developed by the JV turned out to be more complementary to IBM's technology, and the JV was recently disbanded and folded into IBM [Ziegler 1995]. 
Chi, Tailan. (1996) Collaborative Ventures and Value of Learning: Integrating the Transaction Cost and Strategic Option Perspectives on the Choice of Market Entry Modes. Journal of International Business Studies, 27 (2), 285-307. Publisher's Official Version: http://www.jstor.org/stable/155286 Open Access Version: http://kuscholarworks.ku.edu/

${ }^{10}$ The presumed statistical independence of their ex post valuations means that there exist four equally possible states of nature: (i) the MNE values it as $x_{u}$ and the local firm values it as $x_{d}$; (ii) the MNE values it as $x_{d}$ and the local firm values it as $x_{u}$; (iii) both of them value it as $x_{u}$; and (iv) both of them value it as $x_{d}$. Each of these four states has a 0.25 probability of occurring. ${ }^{11}$ This situation can be represented by modifying the probabilities for the four possible states of nature described in the previous note. For instance, if one of the parties is unlikely to value the venture more than the other does, the probability of (i) or (ii) can be set to a value close to zero. ${ }^{12}$ Note that the extra benefit/cost of dissolving the JV was treated as known and incorporated into the values of the two parameters $a$ and $b$ in the basic model defined by (1) and (2) in section 2 . Since this extra benefit/cost is now separated out as a stochastic variable $\tilde{y}$, the values of $a$ and $b$ represent only the nominal prices for acquisition and sell-out, respectively.

${ }^{13}$ An exception is Kogut [1991], who explicitly recognized the linkage between the problem of adverse selection and the potential for JVs to provide the buyer and seller a strategic option. ${ }^{14}$ Although the option to sell out can potentially be used to reduce the appropriation risk, it seems to be a less useful remedy for the problem of information asymmetry. So, we will consider only the option to acquire in deriving the hypotheses in the next section.

${ }^{15} \mathrm{We}$ thank an anonymous reviewer for pointing this out to us. 
Chi, Tailan. (1996) Collaborative Ventures and Value of Learning: Integrating the Transaction Cost and Strategic Option Perspectives on the Choice of Market Entry Modes. Journal of International Business Studies, 27 (2), 285-307. Publisher's Official Version: http://www.jstor.org/stable/155286 Open Access Version: http://kuscholarworks.ku.edu/

\section{REFERENCES}

Akerloff, George A. 1970. The market for 'lemons': Quality, uncertainty, and the market mechanism. Quarterly Journal of Economics, 84: 488-500.

Balakrishnan, Srinivasan \& Mitchell P. Koza. 1993. Information asymmetry, adverse selection and joint ventures: Theory and evidence. Journal of Economic Behavior and Organization, 20(1): 99-117.

Barzel, Yoram \& Wing Suen. 1988. Moral Hazard, monitoring cost, and the choice of contracts. Mimeo, University of Washington.

Beamish, Paul W. \& John C. Banks. 1987. Equity joint ventures and the theory of the multinational enterprise. Journal of International Business Studies, 18(2): 1-16.

Casson, Mark C. 1979. Alternatives to the multinational enterprise, London, UK: Macmillan,.

Chi, Tailan. 1994. Trading in strategic resources: Necessary conditions, transaction cost problems, and choice of exchange structure. Strategic Management Journal, 15(4): 271-290.

. 1996. Performance verifiability and output sharing in collaborative ventures. Management Science, 42(1): 93-109.

Contractor, Farok J. \& Peter Lorange. 1987. Why should firms cooperate? The strategy and economic basis for cooperate ventures. In Farok J. Contractor \& Peter Lorange, editors, Cooperative strategies in international business. Lexington, MA: Lexington Books.

Cox, John C., Stephen A. Ross \& Mark Rubinstein. 1979. Option pricing: A simplified approach. Journal of Financial Economics, 7(3): 229-63.

De Long, J. Bradford, Andrei Shleifer, Lawrence H. Summers \& Robert J. Waldmann. 1992. Noise trader risk in financial markets. Journal of Political Economy, 98(4): 703-738.

Eswaran, Mukesh. \& Ashok Kotwal. 1985. A theory of contractual structure in agriculture. American Economic Review, 75(3): 352-367.

Folta, Timothy B. \& Michael J. Leiblein. 1994. Technology acquisition and the choice of governance by established firms: Insights from option theory in a multinomial logit model. In Dorothy P. Moore, editor, Proceedings of the Annual Meeting of the Academy of Management, 1994: 27-36.

Gomes-Casseres, Benjamin. 1989. Ownership structures of foreign subsidiaries. Journal of Economic Behavior and Organization, 11: 1-25.

. 1990. Firm ownership preferences and host government restrictions: An integrated approach. Journal of International Business Studies, 21(1): 1-22.

Harsanyi, John C. \& Reinhard Selten. 1988. A general theory of equilibrium selection in games. Cambridge, MA: MIT Press. 
Chi, Tailan. (1996) Collaborative Ventures and Value of Learning: Integrating the Transaction Cost and Strategic Option Perspectives on the Choice of Market Entry Modes. Journal of International Business Studies, 27 (2), 285-307. Publisher's Official Version: http://www.jstor.org/stable/155286 Open Access Version: http://kuscholarworks.ku.edu/

Hennart, Jean-Francois. 1982. A theory of multinational enterprise. Ann Arbor: University of Michigan Press.

1988. A transaction costs theory of equity joint ventures. Strategic Management Journal, 9: 361-374.

Hill, Charles W.L. 1992. Strategies for exploiting technological innovations: When and when not to license. Organization Science, 3: 428-441.

Holmstrom, Bengt. 1982. Moral hazard in teams. Bell Journal of Economics, 13: 324-340.

Kamrad, Bardia \& Peter Ritchken. 1991. A lattice claims model for capital budgeting. Management Science, 37(12): 140-149.

Kogut, Bruce. 1991. Joint ventures and the option to expand and acquire. Management Science, 37(1): 19-33.

Leach, J. Chris \& Ananth N. Madhavan. 1992. Intertemporal price discovery by market makers: Active versus passive learning. Journal of Financial Intermediation, 2: 207-235.

Root, Franklin R. 1987. Entry strategies for international markets. Lexington, MA: Lexington Books.

Shan, Weijian. 1990. An empirical analysis of organizational strategies by entrepreneurial hightechnology firms. Strategic Management Journal, 11: 129-139.

Stopford, John M. \& Louis Wells, Jr. 1972. Managing the Multinational Enterprise, London, UK: Longman.

Teece, David J. 1982. Towards an economic theory of the multiproduct firm. Journal of Economic Behavior and Organization, 3: 39-63.

1987. Profiting from technological innovation: Implications for integration, collaboration, licensing and public policy. In David J. Teece, editor, The competitive challenge, studies for industrial innovation and renewal. Cambridge, MA: Ballinger.

Trigeorgis, Lenos. 1991. A log-transformed binomial numerical analysis method for valuing complex multi-option investment. Journal of Financial and Quantitative Analysis, 26: 309326.

1993. The nature of option interactions and the valuation of investments with multiple real options. Journal of Financial and Quantitative Analysis, 28: 1-20.

Williamson, Oliver E. 1975. Markets and hierarchies: Analysis and antitrust implications. New York: Free Press.

Ziegler, Bart. 1995. IBM, Apple, H-P to Disband Taligent; big layoffs loom at software venture. The Wall Street Journal, December 1, B5. 
Chi, Tailan. (1996) Collaborative Ventures and Value of Learning: Integrating the Transaction Cost and Strategic Option Perspectives on the Choice of Market Entry Modes. Journal of International Business Studies, 27 (2), 285-307. Publisher's Official Version: http://www.jstor.org/stable/155286 Open Access Version: http://kuscholarworks.ku.edu/

26

TABLE 1

Values of $V_{0}-\bar{V}_{0}$ Under Different Values of $\bar{x}$ and $\delta$

\begin{tabular}{ccccccc}
\hline & \multicolumn{5}{c}{$\delta=x_{u}-x_{d}$} \\
\cline { 2 - 6 } $\bar{x}=\left(x_{u}+x_{d}\right) / 2$ & 0.0 & 0.1 & 0.2 & 0.3 & 0.4 & 0.5 \\
\hline 1 & 0.4167 & 0.4375 & 0.4583 & 0.4792 & 0.5000 & 0.5208 \\
2 & 0.3333 & 0.3542 & 0.3750 & 0.3958 & 0.4167 & 0.4375 \\
3 & 0.2500 & 0.2708 & 0.2917 & 0.3125 & 0.3333 & 0.3542 \\
4 & 0.1667 & 0.1875 & 0.2083 & 0.2292 & 0.2500 & 0.2708 \\
5 & 0.0833 & 0.1042 & 0.1250 & 0.1458 & 0.1667 & 0.1875 \\
6 & 0.0000 & 0.0208 & 0.0417 & 0.0625 & 0.0833 & 0.1042 \\
7 & -0.0833 & -0.0625 & -0.0417 & -0.0208 & 0.0000 & 0.0208 \\
8 & -0.1667 & -0.1458 & -0.1250 & -0.1042 & -0.0833 & -0.0625 \\
\hline
\end{tabular}

The values of other parameters are assumed as follows: $s=0.5, I_{0}=1$, and $k=0.1$. 


\section{FIGURE 1}

MNE's Expected Payoff as Functions of Uncertainty $(\delta)$ and Ownership Share (s)

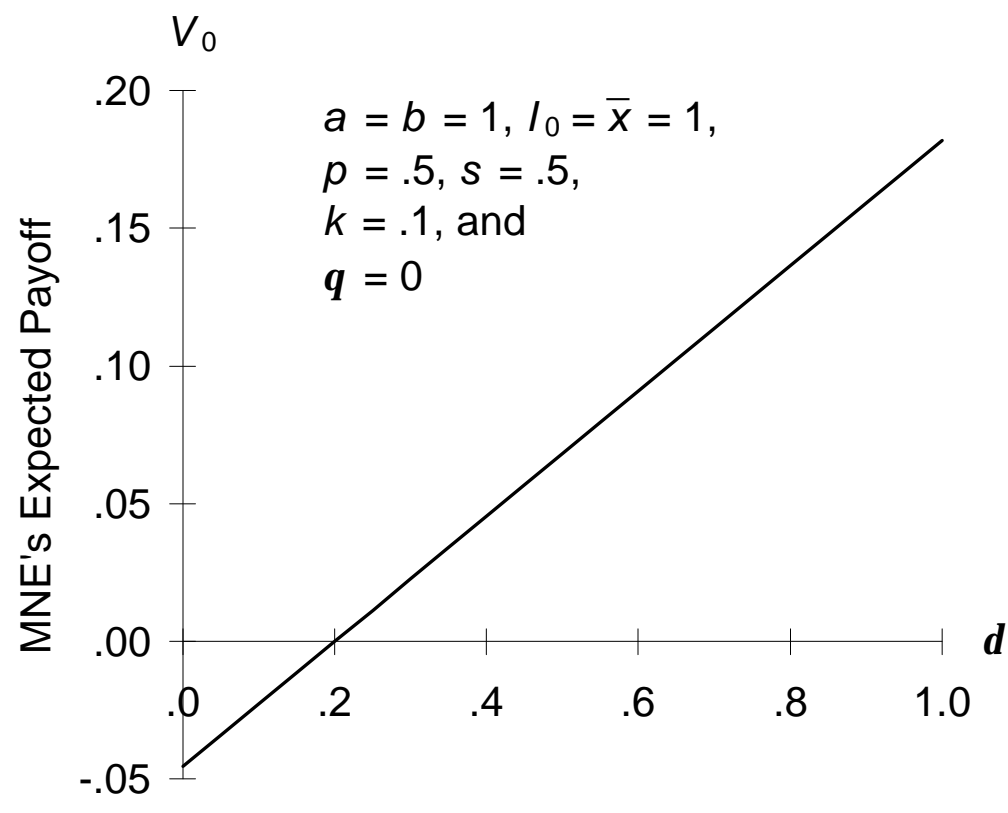

\section{Extent of Uncertainty/Learning Potential}

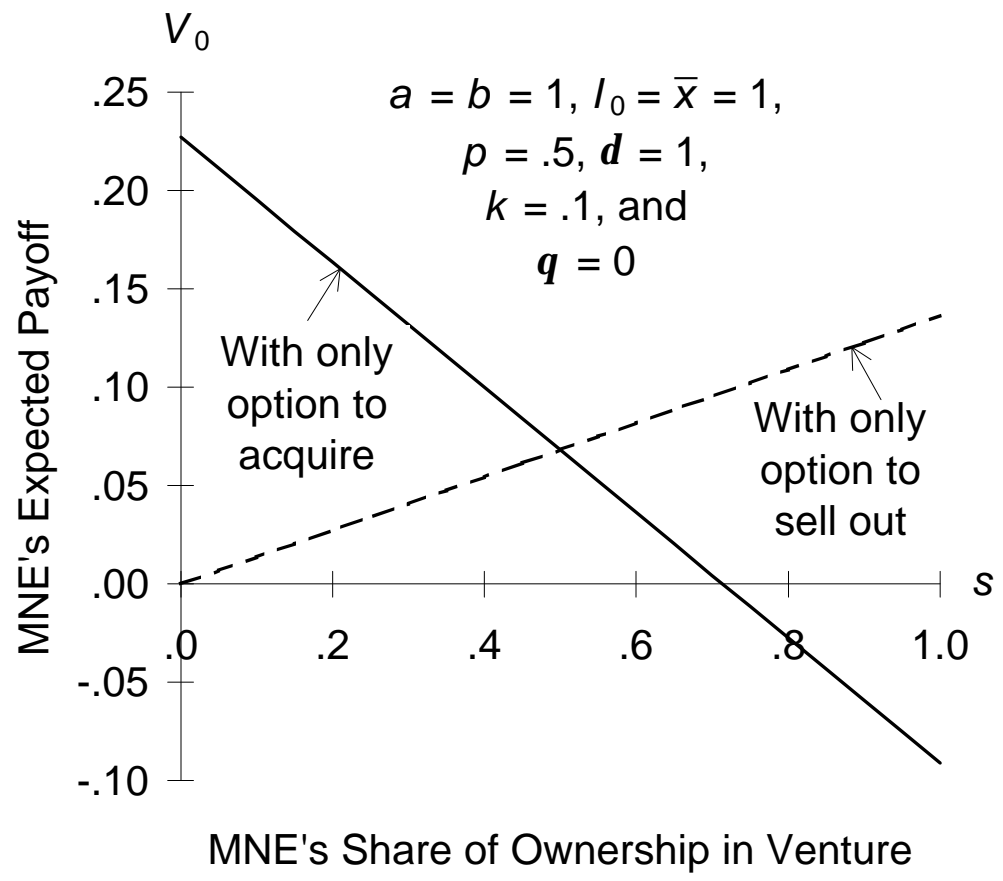




\section{FIGURE 2}
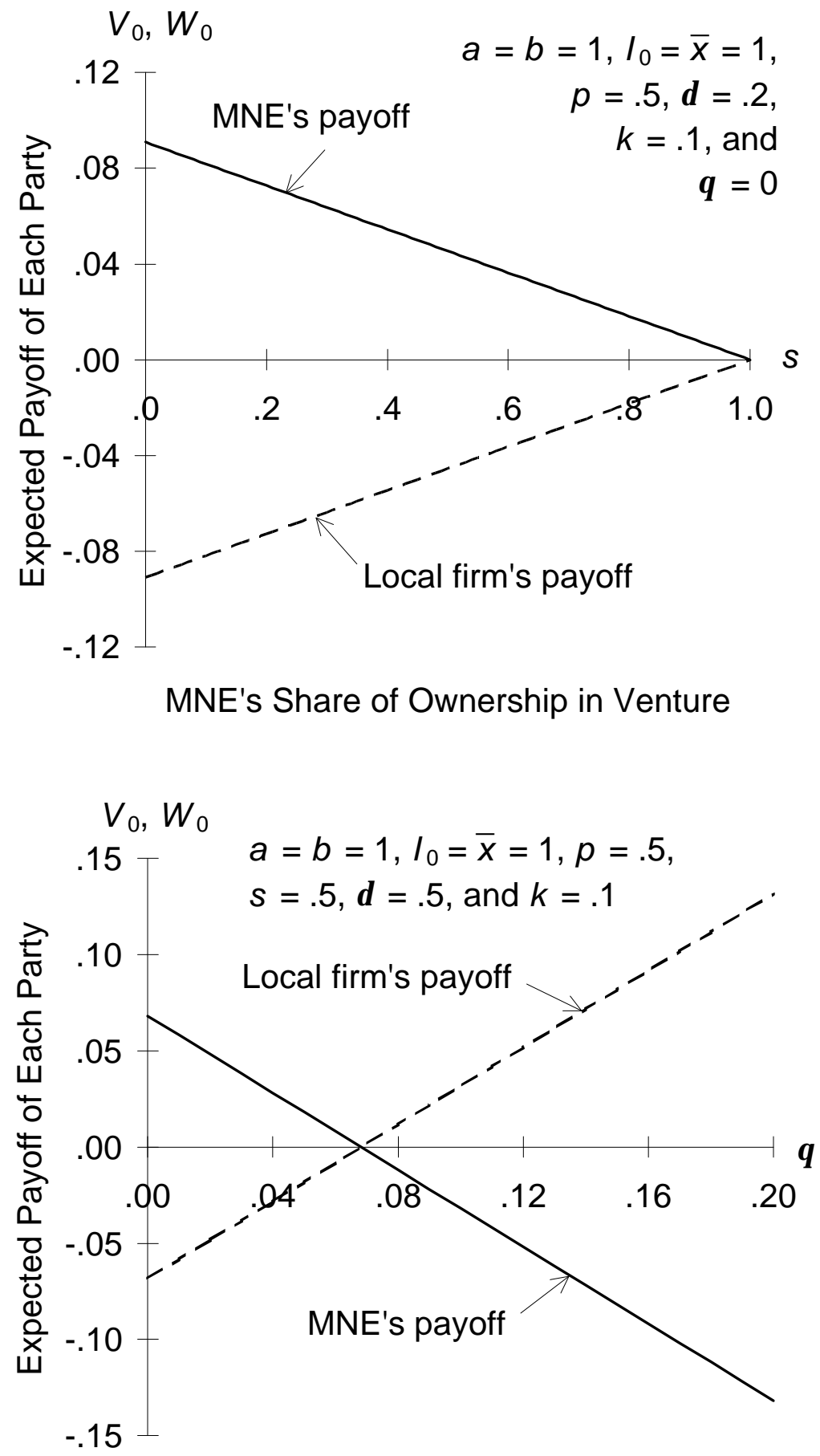

"Option Premium" 


\section{FIGURE 3}

\section{Relationship of MNE's Expected Payoff with Uncertainty about Cost/Benefit of Dissolution}

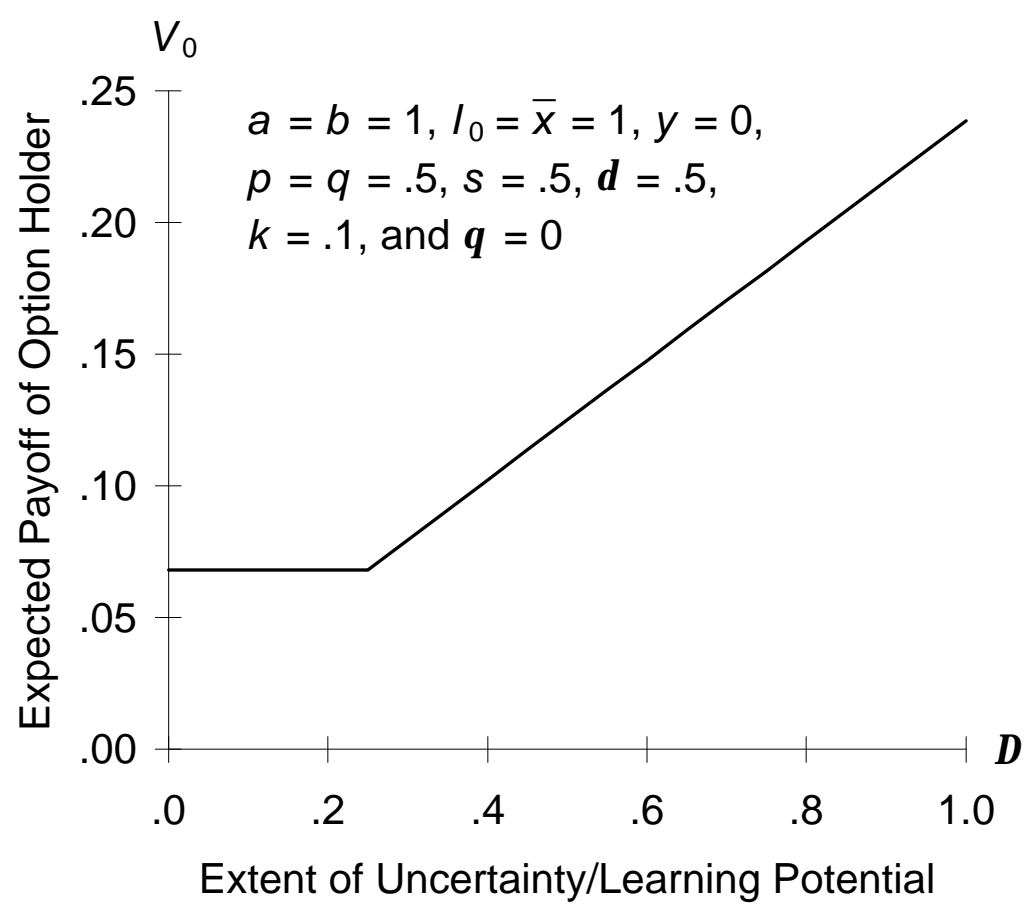

